\title{
Surrogate Measures of Adiposity and Cardiometabolic Risk - Why the Uncertainty? A Review of Recent Meta-Analytic Studies
}

\author{
Seán R Millar*, Ivan J Perry and Catherine M Phillips
}

HRB Centre for Health and Diet Research, Department of Epidemiology and Public Health, University College Cork, Ireland

\begin{abstract}
The increasing obesity epidemic has become a significant public health concern worldwide, as excess body fat has been shown to be strongly related to cardiometabolic risk. Measurement of adiposity is commonly used as an indicator of health and various anthropometric measurement procedures have been proposed to characterise individual susceptibility to cardiometabolic conditions. Although extensive research has attempted to quantify relationships between different adiposity measures and morbidity, results have been conflicting and inconclusive, and considerable controversy still exists as to which anthropometric measurement most accurately defines nonoptimal body fat distribution.In this review we describe the most commonly used indices of general and central adiposity and review the most recently completed meta-analytic studies to determine which adiposity measure is most strongly associated with, and the best discriminator of, type 2 diabetes, cardiovascular disease and mortality.
\end{abstract}

Keywords: Type 2 diabetes; Cardiovascular disease; Obesity; Adiposity

Abbreviations: BMI: Body Mass Index; WC: Waist Circumference; WHR: Waist-Hip Ratio; WHtR: Waist-Height Ratio; T2DM: Type 2 Diabetes; CVD: Cardiovascular Disease; VAT: Visceral Adipose Tissue; BF\%: Body Fat Percentage

\section{Introduction}

\section{Background}

Over the last three decades, the prevalence of overweight and obesity has risen dramatically across world populations, representing a major public health issue [1-3]. The positive, linear relationships between excess adiposity and metabolic risk features such as hypertension, dyslipidaemia and insulin resistance have been repeatedly observed in both cross-sectional and prospective cohort studies [4]. Abundant evidence also supports the association between obesity and a wide range of chronic disorders including type 2 diabetes mellitus (T2DM) and cardiovascular disease (CVD) [5-9]. Morbidity risk increases exponentially with increasing obesity and the consistency of this correlation across all ethnic groups reflects the strength of this relationship [10].

\section{Adiposity and cardiometabolic risk}

The exact mechanism of association between excess body fat and cardiometabolic risk is still poorly understood. Evidence suggests that visceral adipose tissue (VAT) is an important risk factor for the development of metabolic complications, with subcutaneous adipose tissue playing a lesser role [11].Various theories have been proposed to explain this connection. According to the portal-visceral hypothesis, increased release of nonesterified fatty acids into the liver and skeletal muscle cause metabolic dysfunction within these organs, leading to insulin resistance [12]. Alternatively, specific cytokines released by VAT are thought to contribute to cardiometabolic disease through inflammation of vascular tissue [13]. A third premise suggests that genes that predispose preferential deposition of fat in VAT depots independently cause cadiometabolic disease $[14,15]$. As noted by Klein et al. none of these hypotheses are mutually exclusive, and thus it is possible that other unknown mechanisms may also contribute [16].

\section{Clinical measurement of adiposity}

A variety of measurement procedures have been proposed to characterise the relationship between VAT and metabolic risk to enumerate individual susceptibility to cardiometabolic complications. Direct imaging techniques such as computed tomography, magnetic resonance imaging, and dual X-ray absorptiometry (DXA) are used and allow direct quantification of body composition. Other non-imaging methods include hydrodensitometry, bioelectrical impedance and air displacement plethysmography (ADP). However, these procedures require expensive apparatus and specialised personnel, while certain methods may carry an added risk of radiation exposure. Therefore, anthropometry is more frequently utilised as a surrogate measure of body composition in research and clinical settings.

In this review we: (1) discuss the range of surrogate indices currently used; (2) examine results from the most recently completed meta-analytic studies to investigate which measurement of adiposity is most strongly associated with, and the best discriminator of cardiometabolic risk phenotypes, morbidity and mortality.

\section{Surrogate Measures of General and Central Adiposity}

\section{Body mass index}

A measure of general adiposity, body mass index (BMI) is the traditional diagnostic tool in overweight and obesity classification most commonly employed in epidemiological research and healthcare practice. Calculated by dividing a subject's weight by the square of their height, BMI correlates with traditional cardiovascular risk

*Corresponding author: Seán R. Millar, Department of Epidemiology \& Public Health, University College Cork.4th Floor, Western Gateway Building, Western Road, Cork, Ireland, Tel: 353 (0)21 4205520; Fax: 353 (0)21 4205469; E-mail: s.millar@ucc.ie

Received June 12, 2013; Accepted July 27, 2013; Published August 04, 2013

Citation: Millar SR, Perry IJ, Phillips CM (2013) Surrogate Measures of Adiposity and Cardiometabolic Risk - Why the Uncertainty? A Review of Recent MetaAnalytic Studies. J Diabetes Metab S11: 004. doi:10.4172/2155-6156.S11-004

Copyright: @ 2013 Millar SR, et al. This is an open-access article distributed under the terms of the Creative Commons Attribution License, which permits unrestricted use, distribution, and reproduction in any medium, provided the original author and source are credited. 
features and morbidity and mortality [4,17-21].A widely used index, BMI is understood by clinicians and the general public as a whole, is easy to measure and allows non-gender or ethnic-specific risk cutpoints. The World Health Organisation (WHO) classifies a BMI of 25-29.9 as overweight, 30-34.9 as obese class I, 35-39.9 as obese class II, and one equal or above 40 as obese class III [22]. While evidence suggests that risk of T2DM or CVD development is higher in certain populations at a cut-point lower than 25 , a WHO expert consultation committee recently concluded that current classifications should remain [23].Although straightforward to calculate, the measurement of BMI does require the use of a calibrated electronic weighing scale and a stadiometer, which may not always be available in a clinical or field setting. Studies examining self-reported BMI have reported considerable discrepancies [24,25].More importantly, as BMI is a weight-for-height measure, it is unable to distinguish between fat and lean mass, and evidence indicates that it may be less strongly related to VAT than some measures of central obesity [26]. Furthermore, recent research by Flegal et al. [27] found that class I obesity was not associated with higher all-cause mortality and that overweight was related to significantly lower all-cause mortality, a relationship noted in other studies $[28,29]$.In light of these findings, it has been suggested that obesity categorisation based on BMI may be inadequate [30], and that this measure may misclassify adiposity in some individuals $[31,32]$.

\section{Waist circumference}

Waist circumference (WC) has been recommended as a more direct method of central adiposity and VAT assessment. Determined by measuring the circumference of the waist using a flexible tape, numerous studies suggest it to be more strongly related to cardiometabolic features and morbidity than BMI [33-36].Waist circumference measurement has also been adopted by the International Diabetes Federation as a central component for diagnosing the metabolic syndrome (MetS) [37], and is also the only adiposity variable used in three alternative MetS definitions $[38,39]$. However, partly due to a lack of agreement on a universal measurement protocol, its clinical usefulness and superiority over BMI in the prediction of CVD events has been questioned [10,4042].The WHO recommends WC assessment midway between the lowest rib and iliac crest, while the United States National Health and Nutrition Survey (NHANES) III suggests measurement only at the top of the iliac crest [10].Various other sites have been proposed and used, such as umbilical level, lowest rib, and the narrowest point between the last rib and iliac crest [43-46]. Although a report by Ross et al. [47] concluded that the procedure used for estimating WC had minimal effect on morbidity or mortality outcomes, evidence is still equivocal [43].Specific WC cut-offs for determining metabolic risk and defining MetS have been suggested [10], but these are gender and ethnic-specific; numerous studies have shown that regional differences may be important [25], necessitating different cut-points for different populations $[48,49]$.

\section{Waist-Hip ratio}

Waist-hip ratio (WHR) is calculated by dividing WC by hip circumference (HC) and is thought to represent an aspect of body composition, related to CVD risk, not reflected in BMI or WC measurement. This central measure is also associated with cardiometabolic conditions and mortality [50-55], and is the only obesity index included in the WHO working definition of MetS [56]. However, critics of WHR claim that, as a ratio, it is unnecessarily difficult to interpret within a clinical setting [57]. Nevertheless, it should be noted that BMI is also a ratio and is easily used in healthcare practice. The use of a ratio theoretically dispenses with the need for population-specific cut-points [58], although this is still uncertain [59], and current WHO recommendations do specify different WHR cut-offs for men and women [10].From a practical standpoint WHR requires an additional measure which may affect the reliability of this index, although HC measurement is more easily determined than WC measurement. A more problematic concern is that WHR may remain unchanged in an individual even when body fat levels rise, as WC and HC may increase or decrease proportionally [57].

\section{Waist-Height ratio}

A more recently proposed central index, the waist-height ratio (WHtR), is calculated by dividing WC by height. Like the WHR, this adiposity variable is thought to more accurately reflect body fat distribution and several studies have suggested it to be superior to BMI, WC and WHR [60-66]. Unlike WHR, this measure only varies when there is an increase in body composition, as adult height remains relatively static over time. Proponents of WHtR have also suggested that as height may be inversely associated with CVD risk [67], perhaps reflecting genetic predisposition [68] or life exposures [69], inclusion of this variable in an index equation confers greater predictive accuracy [70,71]. As a ratio, WHtR may also require only one, non-gender or ethnic-specific cut-point, which might be additionally attractive from a public health perspective $[61,72]$. However, calculation of this obesity measure also requires accurate height and WC measurement which may affect its practical usefulness. Moreover, some studies have shown WHtR to be minimally superior, or even inferior, to WC in the classification of cardiometabolic risk, and have questioned the measurement of height in addition to WC [73].

\section{Novel indices}

Periodically, novel indices are constructed using manipulations of general or central obesity measures. Among these are Rohrer's Index [74], the Conicity Index [75], the Abdominal Volume Index [76], A Body Shape Index [77] and several equations for determining body fat percentage (BF\%) using sagittal diameter [78] or skin-fold thickness measurements [79,80].Recently, two novel adiposity indices for estimating BF\% were proposed; Bergman et al. [81] determined a DXA validated measure using $\mathrm{HC}$ and height, while Gómez-Ambros et al. [82] designed an equation utilising BMI, age and gender and conducted a comparison study with other anthropometric measures and $\mathrm{BF} \%$ estimated using ADP. However, as many of these novel indices use calculations which are complex, and perhaps difficult to interpret, their clinical utility and general usability must be questioned. Furthermore, there is a lack of research validating their usefulness.

\section{A Meta-Review of Surrogate Measures of Adiposity, Cardiometabolic Risk and Mortality}

\section{Rationale}

Over the last 20 years a considerable number of cross-sectional and prospective studies have attempted to quantify the relationships between indices of adiposity and cardiometabolic risk and mortality. However, results have been conflicting and inconclusive, and considerable controversy still exists as to which of these measures are most strongly related to cardiometabolic conditions. Increasingly, meta-analysis has gained recognition as a useful way of pooling results from numerous cohorts in order to average effect sizes across different studies. The benefits include increasing effective sample sizes, and neutralising the influence of confounding factors, thus allowing for a more precise estimation of an intervention, treatment or measure. 


\section{Selection of meta-analyses}

We concentrated our meta-review on the four most commonly researched measures of general and central adiposity: BMI, WC, WHR and WHtR, and their relationships with cardiometabolic outcomes and mortality. Published meta-analyses relating to these topics from the year 2007 onwards were searched using PubMed, Science Direct, Web of Knowledge, Academic Search Complete, JSTOR and Google Scholar databases. Search terms included a combination of keywords: body mass index or BMI, waist circumference or WC, waist-hip-ratio, WHR or waist-to-hip ratio, waist-height ratio, WHtR, waist-to-height ratio, waist-to-stature ratio or WSR, meta-analysis and systematic review and meta-analysis. There were no language restrictions as long as abstracts were published in English. We included: (1) metaanalyses that compared any two of the four indices of general or central adiposity (either BMI, WC, WHR or WHtR) using male, female, or mixed adults of any ethnic group or age; (2) research using prospective or cross-sectional data; (3) studies with cardiometabolic risk outcomes, including hypertension, systolic or diastolic blood pressure (SBP, DBP), fasting plasma glucose concentrations (FPG), dyslipidaemia, T2DM, CVD (including Coronary Artery Disease (CAD) or mortality. We excluded meta-analyses that included children or adolescents.

\section{Details of included studies}

Twelve meta-analytic studies met inclusion criteria and are presented in table 1 . Five studies included research examining BMI, WC, WHR and WHtR [73,83-86], five investigated three of the four indices [58,70,87-89], one included research examining only WC and WHR [90] and one included BMI and central obesity defined as either WC or WHR [91]. Two examined incident T2DM as an outcome $[73,89]$, one examined incident CVD events [90] and three included incident CAD, CVD or all-cause mortality as an endpoint $[87,88,91]$. Two studies included both prevalent T2DM and hypertension $[58,84]$, one included both incident and prevalent T2DM, hypertension and dyslipidaemia [83], one included incident and prevalent T2DM, hypertension, dyslipidaemia, MetS, and CVD [70], one examined prevalent hypertension [86] and one examined adiposity measure correlations with FPG, SBP, DBP, high density lipoprotein cholesterol (HDL-C), low density lipoprotein cholesterol (LDL-C), total cholesterol (Total-C) and triglycerides (TAG) concentrations [85]. Nine studies included samples from multiple ethnic groups [58,70,73,83,8587,89,91], one included only Europeans [88], one used Asian subjects [84] and one was not stated although included studies were listed [90]. All meta-analyses included subjects of both genders.

The main findings from these studies, stratified by analysis type (relative risks (RR), hazard ratios (HR), odds ratios (OR), area under the receiver operating characteristic curve (ROC) or other analysis type) are presented in table 2 and discussed in the context of cardiometabolic risk and mortality outcomes.

\section{Main Findings from the Meta-Review}

\section{Studies reporting relative risks or hazard ratios}

Six meta-analyses exclusively used prospective data and presented results as RR or HR. Both effect measures assess the risk of an event occurring by comparing the proportion of subjects (with or without an exposure) that develop an outcome [92]. In a meta-regression analysis, using a random effects model restricted to nine cohorts that provided categorical boundaries for BMI, WC, and WHR, Carmienke et al. [87] found the risk of all-cause mortality for BMI to be $27 \%$ comparing obese class II to normal weight. This contrasted with a $32 \%$ probability for WC and a $13 \%$ increased risk for WHR using gender-specific categorical cut-points compared to a normal reference value. Conversely, using overall pooled results from 15 studies comparing sex-specific extreme quantiles, de Koning et al. [90] suggested WHR to be more strongly related to CVD events (1.95, 95\% CI: $1.55-2.44)$ than WC $(1.63,95 \%$ CI: 1.31-2.04) in both men and women, although this difference was not significant. Interestingly, in an individual participant meta-analysis using gender-specific tertiles, Coutinho et al. [91] found the risk for CAD mortality in subjects with central obesity (defined by either WC or WHR) to be $70 \%$, whereas BMI was inversely associated with mortality: $(0.64,95 \%$ CI: 0.59-0.69).However, the use of categorical cut-offs based on arbitrary cut-points - as used by Carmienke - poses problems regarding the validity of comparisons between adiposity measures. Also, as alluded to by Huxley et al. [93], a limitation of the de Koning study was that BMI was not included as a comparison index, and the analysis was not restricted to studies that included both WC and WHR.

Three studies employing prospective data used standardised $\mathrm{Z}$-scores in analysis. Standardising values allows uniform comparison of indices and RR or HR represents the risk associated with a standard deviation (SD) increase in each measure. In a meta-analysis comparing data from 82,864 European subjects, Czernichow et al. [88] reported measures of central obesity to be consistently and positively related to all-cause and CVD mortality. The risk of all-cause mortality was higher for WHR (12\%) compared to WC (5\%) while CVD mortality risk was the same for both measures (15\%).In a multivariate-adjusted model a one SD increase in BMI appeared to confer protection against allcause mortality $(0.95,95 \%$ CI: 0.91-0.99), and showed no association with CVD related death $(1.05,95 \%$ CI: $0.98-1.14)$.Using pooled RR to examine index relationships with T2DM, Kodama et al. [94] found WC (63\%) and WHtR (62\%) to have a modest, but significantly greater association compared to BMI (55\%) and WHR (52\%) in both men and women, whereas Vazquez et al. [89] observed similar diabetes risk for BMI, WC, and WHR (87-88\%) using overall pooled effects from 32 cohorts.

\section{Studies reporting results from area under the receiver operating characteristic curve analysis}

Five meta-analytic studies reported results from ROC analysis. The ROC curve is a graphical representation of the association between sensitivity and specificity. The area under the curve (AUC) provides a scale from 0.5 to 1.0 (with 0.5 representing random chance and 1.0 indicating perfect discrimination) which allows comparison of the predictive abilities of different adiposity measures [92]. In a metaanalysis of 31 prospective or cross-sectional studies which measured WHtR and either BMI or WC, Ashwell et al. [70] demonstrated WHtR to be a better discriminator than both BMI and WC for T2DM, hypertension, dyslipidaemia, MetS and CVD. Pooled results suggested that WC provided improved discrimination for all outcomes by $3 \%$ $(\mathrm{P}<0.05)$, compared to $\mathrm{BMI}$, with WHtR showing an average AUC $4-5 \%$ larger $(\mathrm{P}<0.01)$ than BMI. Results stratified by gender and cardiometabolic outcomes showed similar relationships. Comparable findings were reported by Mohan [86], using cross-sectional data from the Obesity in Asia Collaboration. All central measures were found to be better predictors of hypertension. Although the authors concluded that differences in AUCs were minimal, the WHtR had the highest discriminatory capacity compared to BMI in males (AUC for $\mathrm{WHtR}=0.67$ vs. AUC for $\mathrm{BMI}=0.63$ ) and females (AUC for $\mathrm{WHtR}=0.71$ vs. $\mathrm{AUC}$ for $\mathrm{BMI}=0.66$ ). Conversely, Nyamdorj et al. [84] found the AUC to be larger for BMI to discriminate subjects 
Citation: Millar SR, Perry IJ, Phillips CM (2013) Surrogate Measures of Adiposity and Cardiometabolic Risk - Why the Uncertainty? A Review of Recent Meta-Analytic Studies. J Diabetes Metab S11: 004. doi:10.4172/2155-6156.S11-004

Page 4 of 11

\begin{tabular}{|c|c|c|c|c|c|c|}
\hline Study reference & $\begin{array}{l}\text { Number of } \\
\text { studies }\end{array}$ & Population & Total subjects & Indices examined & Outcomes & Analysis type \\
\hline $\begin{array}{l}\text { Ashwell et al. } \\
(2012)\end{array}$ & 31 & $\begin{array}{l}4 \text { Europe } \\
2 \text { South } \\
\text { America } \\
2 \text { Australasia } \\
6 \text { Asia } \\
2 \text { Middle-East } \\
1 \text { Caribbean } \\
14 \text { other }\end{array}$ & $\begin{array}{l}123,231 \text { men } \\
182,620 \\
\text { women }\end{array}$ & BMI, WC, WHtR & $\begin{array}{l}\text { Incident and prevalent T2DM, } \\
\text { Hypertension, Dyslipidaemia, } \\
\text { MetS, CVD }\end{array}$ & Pooled ROC analysis \\
\hline $\begin{array}{l}\text { Carmienke et al. } \\
\text { (2013) }\end{array}$ & 18 & $\begin{array}{l}6 \text { Europe } \\
10 \text { North } \\
\text { America } \\
2 \text { Australasia }\end{array}$ & $\begin{array}{l}693,739 \\
\text { men and } \\
\text { women }\end{array}$ & BMI, WC, WHR & All-cause mortality & Pooled RR using categorical variables \\
\hline $\begin{array}{l}\text { Coutinho et al. } \\
(2011)\end{array}$ & 5 & $\begin{array}{l}2 \text { Europe } \\
2 \text { North } \\
\text { America } \\
1 \text { Asia }\end{array}$ & $\begin{array}{l}15,923 \\
(59 \% \text { men })\end{array}$ & $\begin{array}{l}\text { BMI, Central obesity } \\
\text { defined as WC or } \\
\text { WHR }\end{array}$ & CAD mortality & $\begin{array}{l}\text { Individual participant meta-analysis } \\
\text { HR by obesity tertiles }\end{array}$ \\
\hline $\begin{array}{l}\text { Czernichow et al. } \\
(2011)\end{array}$ & 9 & Europe & $\begin{array}{l}82,864 \\
(54-62 \% \\
\text { women })\end{array}$ & BMI, WC, WHR & All-cause and CVD mortality & $\begin{array}{l}\text { Individual participant meta-analysis } \\
\text { HR comparing upper quintiles to lower } \\
\text { quintiles and for a } 1 \text { SD increase in each } \\
\text { index } \\
\text { ROC and relative integrated discrimination } \\
\text { improvement statistics (RIDI) }\end{array}$ \\
\hline $\begin{array}{l}\text { de Koning et al. } \\
(2007)\end{array}$ & 15 & Not stated & $\begin{array}{l}258,114 \\
(35.7 \% \text { men })\end{array}$ & WC, WHR & Incident CVD events & $\begin{array}{l}\text { Pooled RR comparing highest to lowest } \\
\text { quantiles of WC and WHR }\end{array}$ \\
\hline $\begin{array}{l}\text { Huxley et al. } \\
(2008)\end{array}$ & 21 & $\begin{array}{l}\text { Asian }(73 \%) \\
\text { Caucasian } \\
(27 \%)\end{array}$ & $\begin{array}{l}>263,000 \\
\text { men and } \\
\text { women }\end{array}$ & BMI, WC, WHR & Prevalent T2DM, Hypertension & $\begin{array}{l}\text { Individual participant meta-analysis } \\
\text { OR stratified by ethnicity }\end{array}$ \\
\hline $\begin{array}{l}\text { Kodama et al. } \\
(2012)\end{array}$ & 15 & $\begin{array}{l}8 \text { Western } \\
7 \text { Non-Western }\end{array}$ & $\begin{array}{l}120,012 \\
(\text { men } 21-78 \%)\end{array}$ & $\begin{array}{l}\text { BMI, WC, WHR, } \\
\text { WHtR }\end{array}$ & Incident T2DM & Pooled RR for $1 \mathrm{SD}$ increase in each index \\
\hline Lee et al. (2008) & 10 & $\begin{array}{l}1 \text { Europe } \\
7 \text { Asian } \\
1 \text { Caribbean } \\
1 \text { Iran }\end{array}$ & $\begin{array}{l}88,514 \\
\text { (54\% women) }\end{array}$ & $\begin{array}{l}\text { BMI, WC, WHR, } \\
\text { WHtR }\end{array}$ & $\begin{array}{l}\text { Incident and prevalent T2DM, } \\
\text { Hypertension, Dyslipidaemia }\end{array}$ & Pooled ROC analysis \\
\hline Mohan (2008) & 19 & $\begin{array}{l}\text { Asian } \\
(62.8 \%) \\
\text { Caucasian } \\
(36.7 \%) \\
\text { Pacific } \\
\text { Islanders } \\
(0.5 \%)\end{array}$ & $\begin{array}{l}>173,709 \\
\text { (53\% women) }\end{array}$ & $\begin{array}{l}\text { BMI, WC, WHR, } \\
\text { WHtR }\end{array}$ & Prevalent Hypertension & $\begin{array}{l}\text { Individual participant meta-analysis } \\
\text { Adjusted linear regression between indices } \\
\text { and SBP/DBP stratified by ethnicity } \\
\text { OR for hypertension stratified by ethnicity } \\
\text { ROC analysis stratified by ethnicity and } \\
\text { overall pooled results }\end{array}$ \\
\hline $\begin{array}{l}\text { Nyamdorj et al. } \\
(2008)\end{array}$ & 16 & Asia & $\begin{array}{l}9,095 \text { men } \\
11,732 \text { women }\end{array}$ & $\begin{array}{l}\text { BMI, WC, WHR, } \\
\text { WHtR }\end{array}$ & Prevalent T2DM, Hypertension & $\begin{array}{l}\text { Individual participant meta-analysis } \\
\text { OR for } 1 \text { SD increase in each index } \\
\text { ROC analysis }\end{array}$ \\
\hline $\begin{array}{l}\text { van Dijk et al. } \\
(2012)\end{array}$ & 20 & $\begin{array}{l}11 \text { Europe } \\
7 \text { North } \\
\text { America } \\
1 \text { Turkey } \\
1 \text { Australasia }\end{array}$ & $\begin{array}{l}21,139 \text { men } \\
24,139 \text { women }\end{array}$ & $\begin{array}{l}\text { BMI, WC, WHR, } \\
\text { WHtR }\end{array}$ & $\begin{array}{l}\text { Prevalent FPG, SBP, DBP, } \\
\text { HDL-C, LDL-C, Total-C, TAG }\end{array}$ & $\begin{array}{l}\text { Pooled mean Pearson correlation } \\
\text { coefficients between each index and } \\
\text { cardiometabolic features }\end{array}$ \\
\hline $\begin{array}{l}\text { Vazquez et al. } \\
\text { (2007) }\end{array}$ & 32 & $\begin{array}{l}9 \text { Europe } \\
12 \text { North } \\
\text { America } \\
4 \text { Asia } \\
7 \text { Other }\end{array}$ & $\begin{array}{l}72-31,702 \\
\text { men and } \\
\text { women }\end{array}$ & BMI, WC, WHR & Incident T2DM & $\begin{array}{l}\text { Pooled RR for a } 1 \text { SD increase in each } \\
\text { index }\end{array}$ \\
\hline
\end{tabular}

Table 1: Details of meta-analyses and cardiometabolic outcomes.

with hypertension but not T2DM.In this study, which included over 20,000 subjects, AUCs for WHtR in relation to prevalent diabetes were greater than BMI in both genders, although not statistically different. Similar results were again confirmed in a pooled analysis of 10 studies comparing BMI, WC, WHR and WHtR discriminatory abilities for incident and prevalent T2DM, hypertension, and dyslipidaemia. Lee et al. [83] noticed all central obesity measures to be better classifiers, with the WHtR showing the largest AUCs for all cardiometabolic outcomes. However, statistical differences between WHtR and BMI were noticed only in men for T2DM (AUC for WHtR $=0.726$ vs. AUC for $\mathrm{BMI}=0.672 \mathrm{P}<0.01$ ) and hypertension (AUC for $\mathrm{WHtR}=0.684$ vs. AUC for $\mathrm{BMI}=0.641 \mathrm{P}<0.04)$. Of note, within each of these four studies, AUCs for both general and/or central obesity measures were greater in women than men. Conversely Czernichow et al. [88] found no clinically relevant difference between BMI, WC, and WHR comparing predictive ability for all-cause or CVD mortality. Relative integrated 
Citation: Millar SR, Perry IJ, Phillips CM (2013) Surrogate Measures of Adiposity and Cardiometabolic Risk - Why the Uncertainty? A Review of Recent Meta-Analytic Studies. J Diabetes Metab S11: 004. doi:10.4172/2155-6156.S11-004

Page 5 of 11

\begin{tabular}{|c|c|c|c|}
\hline Study reference & Outcome & Results & Comments \\
\hline \multicolumn{4}{|c|}{ Studies reporting RR or HR } \\
\hline $\begin{array}{l}\text { Carmienke et al. } \\
(2013)\end{array}$ & All-cause mortality & $\begin{array}{l}\text { 'BMI: } 1.27(1.21-1.33) \\
{ }^{2} \text { WC: } 1.32(1.22-1.43) \\
{ }^{2} \text { WHR: } 1.13(1.11-1.59) \\
\text { 'Obese class II compared to normal } \\
\text { weight } \\
{ }^{2} \text { Gender-specific categorical cut-point } \\
\text { compared to normal reference }\end{array}$ & $\begin{array}{l}\text { Meta-regression analysis restricted to nine cohorts that provided RR } \\
\text { and } 95 \% \mathrm{Cls} \text { and defined category boundaries for adiposity measures } \\
\text { All measures showed similar risk patterns for upper quartiles in } \\
\text { comparison to reference quartiles } \\
\text { Patterns of general and abdominal obesity remained significantly } \\
\text { associated with mortality when adjusted for the other }\end{array}$ \\
\hline \multirow{2}{*}{$\begin{array}{l}\text { Coutinho et al. } \\
(2011)\end{array}$} & \multirow{2}{*}{ CAD mortality } & $\begin{array}{l}\text { Overall pooled RR comparing upper to } \\
\text { lower obesity tertiles } \\
\text { (gender-specific): }\end{array}$ & \multirow{2}{*}{$\begin{array}{l}\text { Central obesity was associated with mortality whereas BMI was } \\
\text { inversely associated with mortality } \\
\text { Central obesity was also associated with higher mortality in a subset } \\
\text { of subjects with normal BMI }\end{array}$} \\
\hline & & $\begin{array}{ll}\text { BMI: } & 0.64(0.59-0.69) \\
\text { WC/WHR: } 1.70(1.58-1.83)\end{array}$ & \\
\hline \multirow{2}{*}{$\begin{array}{l}\text { Czernichow et al. } \\
(2011)\end{array}$} & All-cause mortality & $\begin{array}{l}\text { Multivariate adjusted } \mathrm{HR} \text { for } 1 \mathrm{SD} \\
\text { increase: } \\
\text { BMI: } 0.95(0.91-0.99) \\
\text { WC: } 1.05(1.00-1.09) \\
\text { WHR: } 1.12(1.06-1.18)\end{array}$ & \multirow{2}{*}{$\begin{array}{l}\text { Measures of central obesity were more strongly associated with an } \\
\text { increased risk of CVD mortality } \\
\text { BMI was related to CVD mortality in age and gender adjusted models } \\
\text { only }\end{array}$} \\
\hline & CVD mortality & $\begin{array}{l}\text { Multivariate adjusted HR for } 1 \mathrm{SD} \\
\text { increase: } \\
\text { BMI: } 1.05(0.98-1.14) \\
\text { WC: } 1.15(1.05-1.25) \\
\text { WHR: } 1.15(1.04-1.27)\end{array}$ & \\
\hline $\begin{array}{l}\text { de Koning et al. } \\
(2007)\end{array}$ & Incident CVD events & $\begin{array}{l}\text { Overall risk estimate comparing extreme } \\
\text { gender-specific quantiles for each } \\
\text { measure: } \\
\text { WC: } 1.63(1.31-2.04) \\
\text { WHR: } 1.95(1.55-2.44)\end{array}$ & $\begin{array}{l}\text { Results suggested that WHR was more strongly associated with CVD } \\
\text { events than WC, though differences were not statistically significant } \\
\text { Analysis was not restricted to studies that reported both WC and WHR }\end{array}$ \\
\hline $\begin{array}{l}\text { Kodama et al. } \\
(2012)\end{array}$ & Incident T2DM & $\begin{array}{l}\text { Pooled RR for a } 1 \text { SD increase } \\
\text { (men and women combined): } \\
\text { BMI: } 1.55(1.43-1.69) \\
\text { WC: } 1.63(1.49-1.79) \\
\text { WHR: } 1.52(1.40-1.66) \\
\text { WHtR: } 1.62(1.48-1.78)\end{array}$ & $\begin{array}{l}\text { WC and WHtR showed a modest but significantly greater association } \\
\text { with T2DM compared to BMI or WHR but measuring height in addition } \\
\text { to WC appeared to have no additional benefit }\end{array}$ \\
\hline $\begin{array}{l}\text { Vazquez et al. } \\
(2007)\end{array}$ & Incident T2DM & $\begin{array}{l}\text { Pooled RR for a } 1 \text { SD increase: } \\
\text { BMI: } 1.87(1.67-2.10) \\
\text { WC: } 1.87(1.58-2.20) \\
\text { WHR: } 1.88(1.61-2.19)\end{array}$ & $\begin{array}{l}\text { Similar associations were noted for all obesity indices with incident } \\
\text { T2DM }\end{array}$ \\
\hline \multicolumn{4}{|c|}{ Studies reporting ROC values } \\
\hline $\begin{array}{l}\text { Ashwell et al. } \\
(2012)\end{array}$ & $\begin{array}{l}\text { Incident and prevalent T2DM, } \\
\text { Hypertension, Dyslipidaemia, } \\
\text { MetS, CVD }\end{array}$ & 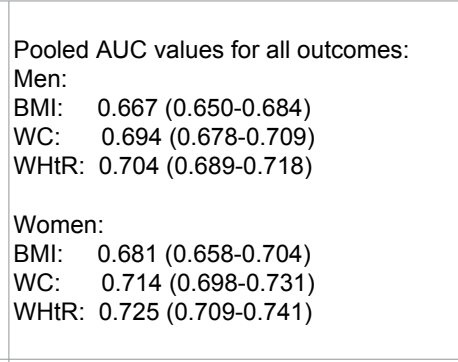 & $\begin{array}{l}\text { For all five specific health outcomes, WHtR had a greater } \\
\text { discriminatory power compared with BMI } \\
\text { Statistical comparison of AUC values of abdominal obesity with } \\
\text { BMI indicated that both WHtR and WC were significantly better at } \\
\text { discriminating T2DM risk } \\
\text { Compared with BMI, WC improved discrimination of adverse } \\
\text { outcomes by } 3 \%(\mathrm{P}<0.05) \text { and WHtR improved discrimination by } \\
4-5 \%(\mathrm{P}<0.01) \\
\text { Discriminatory ability was greater in women }\end{array}$ \\
\hline \multirow{2}{*}{$\begin{array}{l}\text { Czernichow et al. } \\
(2011)\end{array}$} & All-cause mortality & $\begin{array}{ll}\text { BMI: } & 0.847(0.840-0.855) \\
\text { WC: } & 0.847(0.839-0.855) \\
\text { WHR: } & 0.848(0.840-0.856)\end{array}$ & \multirow{2}{*}{$\begin{array}{l}\text { No clinically relevant difference in discrimination capabilities were } \\
\text { observed between the three examined adiposity indices and all cause } \\
\text { or CVD related mortality }\end{array}$} \\
\hline & CVD mortality & $\begin{array}{ll}\text { BMI: } & 0.868(0.856-0.880) \\
\text { WC: } & 0.868(0.856-0.880) \\
\text { WHR: } & 0.868(0.856-0.880)\end{array}$ & \\
\hline Lee et al. (2008) & $\begin{array}{l}\text { Incident and prevalent T2DM, } \\
\text { Hypertension, Dyslipidaemia }\end{array}$ & 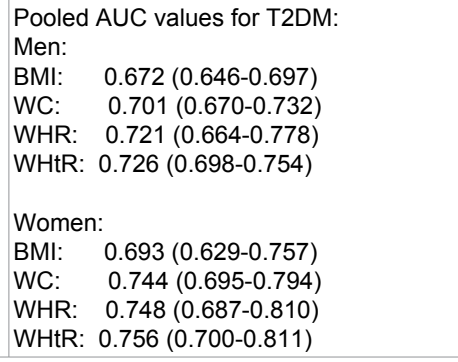 & $\begin{array}{l}\text { WHtR was the best discriminator for T2DM, hypertension and } \\
\text { dyslipidaemia in both genders } \\
\text { Statistical differences between BMI and WHtR were noticed only in } \\
\text { men for T2DM and hypertension } \\
\text { Higher pooled AUC values were observed in females compared to } \\
\text { males suggesting that discrimination is more precise in women } \\
\text { Statistical evidence supports the superiority of measures of central } \\
\text { obesity over BMI for detecting CVD risk factors in men and women }\end{array}$ \\
\hline
\end{tabular}


Citation: Millar SR, Perry IJ, Phillips CM (2013) Surrogate Measures of Adiposity and Cardiometabolic Risk - Why the Uncertainty? A Review of Recent Meta-Analytic Studies. J Diabetes Metab S11: 004. doi:10.4172/2155-6156.S11-004

Page 6 of 11

\begin{tabular}{|c|c|c|c|}
\hline Mohan (2008) & Prevalent Hypertension & 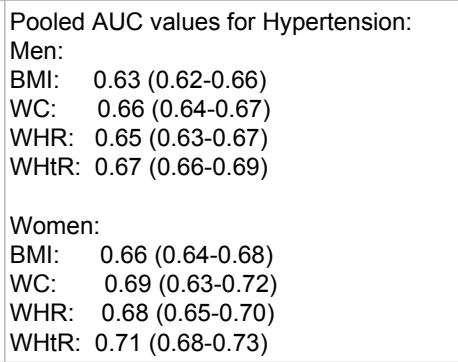 & $\begin{array}{l}\text { Measures of central obesity tended to be better discriminators of } \\
\text { hypertension in both gender } \\
\text { Overall - WHtR had the highest discriminatory capability } \\
\text { Heterogeneity in associations and discriminatory capacity were } \\
\text { observed between different ethnic populations }\end{array}$ \\
\hline $\begin{array}{l}\text { Nyamdorj et al. } \\
(2008)\end{array}$ & Prevalent T2DM, Hypertension & $\begin{array}{l}\text { Pooled AUC values for T2DM: } \\
\text { Men: } \\
\text { BMI: }\end{array}$ & $\begin{array}{l}\text { AUC values for T2DM were slightly higher for WHtR in both genders } \\
\text { and for WC in women only, compared to BMI, but were not statistically } \\
\text { different } \\
\text { AUC values for hypertension were greater for BMI in both genders }\end{array}$ \\
\hline \multicolumn{4}{|c|}{ Studies reporting OR or other statistic } \\
\hline \multirow{2}{*}{$\begin{array}{l}\text { Czernichow et al. } \\
\text { (2011) }\end{array}$} & All-cause mortality & $\begin{array}{l}\text { RIDI statistic: } \\
\text { BMI compared to WC: } 0.150(0.140- \\
0.160) \\
\text { BMI compared to WHR: } 0.335(0.321- \\
0.348) \\
\text { WC compared to WHR: } 0.184(0.175- \\
0.193)\end{array}$ & \multirow{2}{*}{$\begin{array}{l}\text { There was a modest }(0.1 \%) \text { enhancement in discriminative capability } \\
\text { using WHR compared to BMI } \\
\text { The advantage of using WHR compared to WC was also marginal } \\
\text { Models combining two adiposity indices did not provide improvement } \\
\text { in the prediction of mortality }\end{array}$} \\
\hline & CVD mortality & $\begin{array}{l}\text { RIDI statistic: } \\
\text { BMI compared to WC: } 0.543(0.524- \\
0.563) \\
\text { BMI compared to WHR: } 0.265(0.263- \\
0.295) \\
\text { WC compared to WHR }-0.276(-0.302- \\
\text { to }-0.250)\end{array}$ & \\
\hline $\begin{array}{l}\text { Huxley et al. } \\
(2008)\end{array}$ & Prevalent T2DM, Hypertension & $\begin{array}{l}0.5 \text { SD increment increase in BMI } \\
\text { associated with } 20-30 \% \text { odds for T2DM } \\
\text { in Asian subjects } \\
0.5 \text { SD increment increase in WC or } \\
\text { WHR associated with } 40 \% \text { increased } \\
\text { odds in Asian subjects }\end{array}$ & $\begin{array}{l}\text { Odds of hypertension were similar for all measures of general and } \\
\text { central adiposity } \\
\text { Heterogeneity was observed between obesity/morbidity associations } \\
\text { and ethnicity }\end{array}$ \\
\hline $\begin{array}{l}\text { Nyamdorj et al. } \\
(2008)\end{array}$ & Prevalent T2DM, Hypertension & 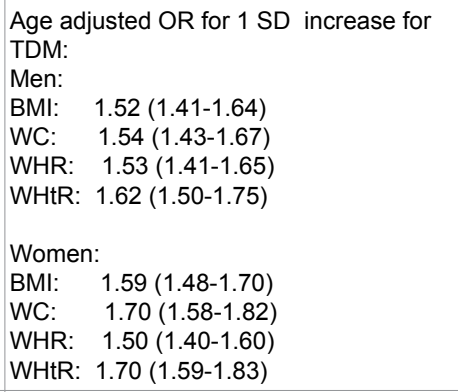 & $\begin{array}{l}\text { WHtR showed a stronger association with T2DM compared to BMI but } \\
\text { all indices were equally strongly associated with hypertension }\end{array}$ \\
\hline $\begin{array}{l}\text { van Dijk et al. } \\
(2012)\end{array}$ & $\begin{array}{l}\text { Prevalent FPG, SBP, DBP, } \\
\text { HDL-C, } \\
\text { LDL-C, Total-C, TAG }\end{array}$ & 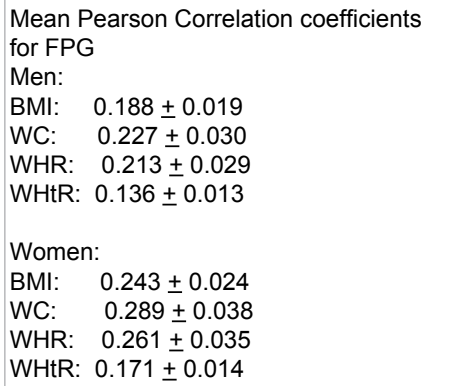 & $\begin{array}{l}\text { WC had the strongest correlation with all CVD risk factors in both men } \\
\text { and women, except for HDL-C and LDL-C in men } \\
\text { When comparing BMI to WC the latter showed significantly better } \\
\text { correlation to CVD risk factors, except for diastolic BP in women and } \\
\text { HDL-C and Total-C in men }\end{array}$ \\
\hline
\end{tabular}

Table 2: Results from meta-analyses - stratified by analysis type. 
discrimination improvement analysis, which measures the percentage of increased discrimination when an extra variable is added to a prediction model, identified a modest $(0.1 \%)$ change when WHR was substituted for BMI. However, differences in models containing WC or both WC and WHR were marginal.

\section{Studies reporting odds ratios or other statistic}

Two studies reported effect measures as OR, which represent the ratio of the odds of an event occurring in one group, to the odds of it occurring in another. Although similar in interpretation to RR, OR generally overestimate associations between variables but are an approximation of the RR when the rare disease assumption holds [92].In an individual participant meta-analysis which stratified effect measures by ethnicity, Huxley et al. [58] found a 0.5 SD increment increase in BMI to be associated with a $20-30 \%$ increased odds for prevalent T2DM in Asian subjects. The corresponding odds using WC or WHR were $40 \%$.However, OR for prevalent hypertension were comparable between BMI, WC and WHR. Similarly, Nyamdorj et al. [84] observed both general and central obesity measures to be equally related to hypertension, while WHtR was more strongly associated with prevalent T2DM in men and women. Finally, research conducted by van Dijk et al. [85], which measured the Pearson product-moment correlation (an appraisal of the linear dependence of two variables [92]) showed WC to have the strongest correlation with all CVD risk factors in both genders with the exception of HDL-C and LDL-C in men.

\section{Recent Research}

Although this review concentrated on meta-analytic studies, recent research employing large cohorts should also be considered in the context of obesity measures and cardiometabolic risk.In a crosssectional study, utilising data from 7,447 Spanish men and women aged 55-80, Guasch-Ferré et al. [95] concluded that measures of abdominal obesity showed greater discriminative abilities for T2DM, impaired FPG, dyslipidaemia and MetS. The AUC values for WHtR and WC were significantly higher than AUCs for BMI with respect to all metabolic risk factors, except hypertension. However, as results were not stratified by gender, potential differences in index discrimination between men and women were not determined. In another Spanish study, using prospective data from 37,733 subjects ( $63 \%$ women), Huerta et al. [96] found both general and central obesity to be independently associated with T2DM.The WHtR index showed the largest AUCs in both men and women (AUC $=0.687$ and 0.776 ) compared to $\mathrm{BMI}$ (AUC $=0.676$ and 0.759) respectively, although classification differences were small. Associations between central obesity measures and incident T2DM were greater in women only, with BMI showing the strongest association for diabetes in men. Similar results were demonstrated by the Interact Consortium, a pan-European cohort examining incident T2DM involving 340,234 participants. In this study, Langenberg et al. [97] also reported BMI and WC to be independently associated with T2DM.The relationship between WC and T2DM was especially strong in women, leading the authors to recommend central obesity measurement as an effective strategy for risk stratification. Gender heterogeneity was additionally noted by Wannamethee et al. [98] in a seven year prospective study which examined BMI, WC and WHR for predicting incident T2DM in 6,923 older men and women. The ROC analysis revealed similar discrimination for BMI and WC in males (AUC $=0.726$ and 0.713 ) respectively, with WHR showing the least predictive ability ( $\mathrm{AUC}=0.656$ ). In females, $\mathrm{WC}$ was a significantly better classifier $(\mathrm{AUC}=0.780 \quad \mathrm{P}<0.01)$ compared to both $\mathrm{BMI}$ (AUC=0.733) or WHR (AUC=0.728; $\mathrm{P}<0.001$ for both).Conversely, in a cross-sectional study of 12,294 adults, Mooney et al. [99] reported similar discriminatory capabilities for all indices for prevalent risk factors in both genders. Central obesity related measures were better predictors of impaired FPG whereas BMI was the best predictor of hypertension.

\section{Discussion}

Of the seven meta-analyses included in this review that reported effect measures as RR, HR, or OR (and which included indices of both general and central adiposity), five concluded that central obesity measures (either WC, WHR or WHtR) were more strongly associated with most cardiometabolic outcomes or mortality [58,73,84,88,91], while two suggested that general and central adiposity indices showed similar risk patterns $[87,89]$.Of the five that reported results from ROC analysis, one indicated that central obesity measures were significantly better discriminators than BMI [70]; one reported that they were statistically greater in men only [83]; two determined that AUCs were larger for central indices, but not significantly so, or that differences were minimal $[84,86]$; and one concluded that there was no clinically relevant difference in predictive abilities between either BMI, WC or WHR [88].The results from this meta-review may suggest that central adiposity measurement is more strongly related to, and a more accurate predictor of certain cardiometabolic outcomes. However, the results are also conflicting. Although, on average, RR, HR or OR were higher for central obesity measures regarding certain endpoints (with the notable exception of hypertension), similar strengths of association were noted in many individual studies. As discussed by Pepe et al. [100], although a strong association is a necessary condition when comparing measures in terms of ability to predict, it is not sufficient, as variables with strong associations may not adequately discriminate between subjects with or without an outcome of interest. Additionally, while two meta-analyses suggested that AUC values were significantly greater for central indices regarding specific outcomes (either both genders or in men only) and the WHtR index was a noticeably better classifier in several, discriminatory differences were modest $(3-5 \%)$ [70,83].Furthermore, as noted by Qiao and Nyamdorj [101], classification distinctions between BMI and central measures are frequently observed in crosssectional research. This is potentially problematic, as cross-sectional data precludes examination of the temporal nature between adiposity measures and CVD risk factors, and it is possible that development of T2DM or CVD may influence body composition in different ways [93].Conversely, although prospective studies are considered a gold standard for observational research, certain limitations remain. Obesity development is a dynamic progression. Heterogeneity between subjects with general and central adiposity may be misclassified in studies with long follow-up periods if the transition from a normal to overweight state is not adequately examined.

Additional factors should also be considered when drawing conclusions from this review.Meta-analysis, while an effective tool within epidemiological research, is not without its limitations. Several studies included numerous comparisons between one or more anthropometric variables and outcomes, and less for others, thus giving some variables an inordinate weight in analysis. Furthermore, as WC measurement has not been standardised internationally, optimal measurement for assessing metabolic risk may be different between included studies, affecting the strength of relationship between central obesity variables and cardiometabolic outcomes. The results from this meta-review also suggest variance in adiposity measure/risk associations between men and women [102], and studies which do not stratify in analysis may over or underestimate effect sizes.Importantly, 
cardiometabolic endpoints may also be classified differently within studies, with several using optimal procedures for outcomes (i.e. the oral glucose tolerance test for T2DM for example) and some using only self-reported diagnosis. Potentially confounding factors such as age and ethncitiy may also influence results $[103,104]$.

\section{Conclusions}

Comparative studies of BMI and central adiposity relationships suggest the latter provides additional information (beyond that which is measured by BMI), as the relationships between BMI and CVD risk factors are attenuated in regression models after the addition of WC, indicating that either central obesity explains the majority of cardiometabolic risk, or that both measures add independent information [103,105]. However, just as critics of central obesity measurement - who claim it as unnecessary, inaccurate, or timeconsuming - neglect to state how much of an increase in predictive accuracy would be clinically relevant, so it is also true that proponents of WC, WHR or WHtR often fail to clarify how much added valuable information these indices might provide over BMI or other variables currently used in T2DM or CVD risk prediction scores.T hese concerns were examined by Klein et al. [16], who determined that measurement of WC in clinical practice would not be trivial, as providing such an assessment competes for the limited time available during patient appraisal, and requires specific training to ensure reliable data are obtained. Nevertheless, WC measurement was recommended as way of identifying a potentially non-trivial number of patients at increased CVD risk who might not otherwise be recognised using conventional methods. Waist circumference, WHR or WHtR could potentially be effective clinical tools for identifying "metabolically unhealthy, nonobese" subjects who might benefit from an intervention or lifestyle therapy, but who would not otherwise be considered for treatment. We have recently shown that assessing both $\mathrm{BF} \%$ and BMI to classify obesity may help identify individuals at greater cardiometabolic risk than BMI alone [106].Subjects classified as obese using both tools had a more metabolically unhealthy profile and were not responsive to dietary intervention.It may be that metabolically unhealthy obese subjects are simply metabolically overburdened and thus no longer dietary responsive, whereas metabolically healthy obese subjects have greater metabolic flexibility to adapt to dietary changes. Therefore, risk stratification based on health phenotypes, using surrogate abdominal measures, may be useful in ascertaining an appropriate therapeutic or intervention strategy. This idea was further explored in a WHO report [10] which suggested that central adiposity measurements, used in conjunction with BMI, might contribute to the development of composite indices for use in specific individuals or populations. Central indices could also add valuable information to screening programmes for undiagnosed cardiovascular conditions, and this might be particularly beneficial in populations without regular access to primary care.

Nevertheless, despite these potential uses, a majority of research continues to demonstrate a strong relationship between BMI and cardiometabolic outcomes. This indicates its continued relevance for determining metabolic risk within a clinical setting. While results from this review suggest that certain central obesity measures may be independently related to, and better classifiers of some cardiometabolic conditions, results are inconclusive. The superiority of central adiposity indices, over BMI, must be questioned as discriminatory differences are not large, none have been conclusively shown to be superior and protocols for measurement and classification cut-offs using central measures are undetermined and may differ between gender and/or ethnic populations. Each of these factors may ultimately determine their efficacy and practical or general usability within healthcare practice. Until these uncertainties have been effectively resolved, the clinical utility of WC, WHR or WHtR as potentially more accurate predictors of cardiometabolic abnormalities, T2DM, CVD and mortality will require further investigation.

\section{References}

1. Caballero B (2007) The global epidemic of obesity: an overview. Epidemiol Rev 29: 1-5.

2. James PT, Rigby N, Leach R; International Obesity Task Force (2004) The obesity epidemic, metabolic syndrome and future prevention strategies. Eur $\mathrm{J}$ Cardiovasc Prev Rehabil 11: 3-8.

3. Finucane MM, Stevens GA, Cowan MJ, Danaei G, Lin JK, et al. (2011) National, regional, and global trends in body-mass index since 1980: systematic analysis of health examination surveys and epidemiological studies with 960 countryyears and 9.1 million participants. The Lancet 377 : 557-567.

4. Guh DP, Zhang W, Bansback N, Amarsi Z, Birmingham CL, et al. (2009) The incidence of co-morbidities related to obesity and overweight: a systematic review and meta-analysis. BMC Public Health 9: 88.

5. Van Gaal LF, Mertens IL, De Block CE (2006) Mechanisms linking obesity with cardiovascular disease. Nature 444: 875-880.

6. Poirier P, Giles TD, Bray GA, Hong Y, Stern JS, et al. (2006) Obesity and cardiovascular disease pathophysiology, evaluation, and effect of weight loss. Arterioscler Thromb Vasc Biol 26: 968-976.

7. Reaven G, Abbasi F, McLaughlin T (2004) Obesity, insulin resistance, and cardiovascular disease. Recent Prog Horm Res 59: 207-223.

8. Kahn SE, Hull RL, Utzschneider KM (2006) Mechanisms linking obesity to insulin resistance and type 2 diabetes. Nature 444: 840-846.

9. Chang SH, Beason TS, Hunleth JM, Colditz GA (2012) A systematic review of body fat distribution and mortality in older people. Maturitas 72: 175-191.

10. WHO (2008) Waist circumference and waist-hip ratio: report of a WHO expert consultation. Geneva.

11. Matsushita Y, Tomita K, Yokoyama T, Mizoue T (2010) Relations between wais circumference at four sites and metabolic risk factors. Obesity (Silver Spring) 18: $2374-2378$.

12. Kabir M, Catalano KJ, Ananthnarayan S, Kim SP, Van Citters GW, et al. (2005) Molecular evidence supporting the portal theory: a causative link between visceral adiposity and hepatic insulin resistance. Am J Physiol Endocrino Metab 288: E454-461.

13. Arsenault BJ, Després JP, Boekholdt SM (2011) Hypertriglyceridemic waist: missing piece of the global cardiovascular risk assessment puzzle? Clinical Lipidology 6: 639-651.

14. Britton KA, Fox CS (2011) Ectopic fat depots and cardiovascular disease. Circulation 124: e837-841.

15. Pausova Z, Syme C, Abrahamowicz M, Xiao Y, Leonard GT, et al. (2009) A common variant of the $F T O$ gene is associated with not only increased adiposity but also elevated blood pressure in French Canadians. Circ Cardiovasc Genet 2: 260-269.

16. Klein S, Allison DB, Heymsfield SB, Kelley DE, Leibel RL, et al. (2012) Waist circumference and cardiometabolic risk: a consensus statement from shaping America's health: Association for Weight Management and Obesity Prevention; NAASO, the Obesity Society; the American Society for Nutrition; and the American Diabetes Association. Obesity (Silver Spring) 15: 1061-1067.

17. Calle EE, Thun MJ, Petrelli JM, Rodriguez C, Heath CW Jr (1999) Body-mass index and mortality in a prospective cohort of U.S. adults. N Engl J Med 341 1097-1105.

18. Jiang J, Ahn J, Huang WY, Hayes RB (2013) Association of obesity with cardiovascular disease mortality in the PLCO trial. Prev Med 57: 60-64.

19. Adams KF, Schatzkin A, Harris TB, Kipnis V, Mouw T, et al. (2006) Overweight obesity, and mortality in a large prospective cohort of persons 50 to 71 years old. N Engl J Med 355: 763-778.

20. Sung KC, Ryu S, Reaven GM; Health Screening Group at Kangbuk Samsung 
Citation: Millar SR, Perry IJ, Phillips CM (2013) Surrogate Measures of Adiposity and Cardiometabolic Risk - Why the Uncertainty? A Review of Recent Meta-Analytic Studies. J Diabetes Metab S11: 004. doi:10.4172/2155-6156.S11-004

Page 9 of 11

Hospital (2007) Relationship between obesity and several cardiovascular disease risk factors in apparently healthy Korean individuals: comparison of body mass index and waist circumference. Metabolism 56: 297-303.

21. Prospective Studies Collaboration, Whitlock G, Lewington $S$, Sherliker $P$, Clarke R, et al. (2009) Body-mass index and cause-specific mortality in 900 000 adults: collaborative analyses of 57 prospective studies. Lancet 373: $1083-$ 1096.

22. [No authors listed] (1995) Physical status: the use and interpretation of anthropometry. Report of a WHO Expert Committee. World Health Organ Tech Rep Ser 854: 1-452.

23. WHO Expert Consultation (2004) Appropriate body-mass index for Asian populations and its implications for policy and intervention strategies. Lance 363: 157-163.

24. Shiely F, Perry IJ, Lutomski J, Harrington J, Kelleher CC, et al. (2010) Tempora trends in misclassification patterns of measured and self-report based body mass index categories--findings from three population surveys in Ireland. BMC Public Health 10: 560.

25. Brestoff JR, Perry IJ, Van den Broeck J (2011) Challenging the role of socia norms regarding body weight as an explanation for weight, height, and BMI misreporting biases: Development and application of a new approach to examining misreporting and misclassification bias in surveys. BMC Public Health 11: 331.

26. Chan DC, Watts GF, Barrett PH, Burke V (2003) Waist circumference, waist-tohip ratio and body mass index as predictors of adipose tissue compartments in men. QJM 96: 441-447.

27. Flegal KM, Kit BK, Orpana H, Graubard BI (2013) Association of all-cause mortality with overweight and obesity using standard body mass index categories: a systematic review and meta-analysis. JAMA 309: 71-82.

28. Curtis JP, Selter JG, Wang Y, Rathore SS, Jovin IS, et al. (2005) The obesity paradox: body mass index and outcomes in patients with heart failure. Arch Intern Med 165: 55-61.

29. Dorner TE, Rieder A (2012) Obesity paradox in elderly patients with cardiovascular diseases. Int J Cardiol 155: 56-65.

30. Viña J, Borras C, Gomez-Cabrera MC (2013) Overweight, obesity, and allcause mortality. JAMA 309: 1679.

31. Gómez-Ambrosi J, Silva C, Galofré JC, Escalada J, Santos S, et al. (2012) Body mass index classification misses subjects with increased cardiometabolic risk factors related to elevated adiposity. Int J Obes (Lond) 36: 286-294.

32. Okorodudu DO, Jumean MF, Montori VM, Romero-Corral A, Somers VK, et al. (2010) Diagnostic performance of body mass index to identify obesity as defined by body adiposity: a systematic review and meta-analysis. Int J Obes (Lond) 34: 791-799.

33. Blaha MJ, Gebretsadik T, Shintani A. Elasy TA (2008) Waist circumference, not the metabolic syndrome, predicts glucose deterioration in type 2 diabetes. Obesity (Silver Spring) 16: 869-874.

34. Brenner DR, Tepylo K, Eny KM, Cahill LE, El-Sohemy A (2010) Comparison of body mass index and waist circumference as predictors of cardiometabolic health in a population of young Canadian adults. Diabetol Metab Syndr 2: 28.

35. Dobbelsteyn C, Joffres M, MacLean D, Flowerdew G (2001) A comparative evaluation of waist circumference, waist-to-hip ratio and body mass index as indicators of cardiovascular risk factors. The Canadian Heart Health Surveys. International journal of obesity and related metabolic disorders: journal of the International Association for the Study of Obesity 25: 652

36. Feller S, Boeing H, Pischon T (2010) Body mass index, waist circumference, and the risk of type 2 diabetes mellitus: implications for routine clinical practice. Dtsch Arztebl Int 107: 470-476.

37. Alberti KG, Zimmet P, Shaw J (2006) Metabolic syndrome--a new world-wide definition. A Consensus Statement from the International Diabetes Federation. Diabet Med 23: 469-480.

38. Grundy SM, Brewer Jr HB, Cleeman JI, Smith Jr SC, Lenfant C, et al. (2004) Definition of metabolic syndrome report of the National Heart, Lung, and Blood Institute/American Heart Association Conference on scientific issues related to definition. Circulation 109: 433-438.

39. Balkau B, Charles MA, Drivsholm T, Borch-Johnsen K, Wareham N, et al. (2002) Frequency of the WHO metabolic syndrome in European cohorts, and an alternative definition of an insulin resistance syndrome. Diabetes Metab 28 : 364-376.

40. Berentzen TL, Jakobsen MU, Halkjaer J, Tjønneland A, Sørensen TI, et al (2011) Changes in waist circumference and the incidence of diabetes in middleaged men and women. PloS one 6: e23104.

41. Liu A, Abbasi F, Reaven GM (2011) Adiposity indices in the prediction of metabolic abnormalities associated with cardiovascular disease in non-diabetic adults. Nutr Metab Cardiovasc Dis 21: 553-560.

42. Després JP, Lemieux I (2006) Abdominal obesity and metabolic syndrome. Nature 444: 881-887.

43. Bosy-Westphal A, Booke CA, Blöcker T, Kossel E, Goele K, et al. (2010) Measurement site for waist circumference affects its accuracy as an index of visceral and abdominal subcutaneous fat in a Caucasian population. J Nutr 140: 954-961.

44. Paula HA, Ribeiro Rde C, Rosado LE, Abranches MV, Franceschini Sdo C (2012) Relationship between waist circumference and supine abdominal height measured at different anatomical sites and cardiometabolic risk factors in olde women. J Hum Nutr Diet 25: 563-568.

45. Lin CC, Yu SC, Wu B-J, Chang DJ (2012) Measurement of waist circumference at different sites affects the detection of abdominal obesity and metabolic syndrome among psychiatric patients. Psychiatry Res 197: 322-326.

46. Mason C, Katzmarzyk PT (2009) Variability in waist circumference measurements according to anatomic measurement site. Obesity (Silver Spring) 17: 1789-1795

47. Ross R, Berentzen T, Bradshaw AJ, Janssen I, Kahn HS, et al. (2008) Does the relationship between waist circumference, morbidity and mortality depend on measurement protocol for waist circumference? Obes Rev 9: 312-325.

48. Lee JS, Kawakubo K, Mori K, Akabayashi A (2007) Effective cut-off values of waist circumference to detect the clustering of cardiovascular risk factors of metabolic syndrome in Japanese men and women. Diab Vasc Dis Res 4: 340 345 .

49. Zhu S, Heymsfield SB, Toyoshima H, Wang Z, Pietrobelli A, et al. (2005) Raceethnicity-specific waist circumference cutoffs for identifying cardiovascular disease risk factors. Am J Clin Nutr 81: 409-415.

50. Dalton M, Cameron AJ, Zimmet PZ, Shaw JE, Jolley D, et al. (2003) Waist circumference, waist-hip ratio and body mass index and their correlation with cardiovascular disease risk factors in Australian adults. J Intern Med 254: 555563.

51. Welborn TA, Dhaliwal SS, Bennett SA (2003) Waist-hip ratio is the dominant risk factor predicting cardiovascular death in Australia. Med J Aust 179: 580585

52. Zhang X, Shu XO, Gao YT, Yang G, Matthews CE, et al. (2004) Anthropometric predictors of coronary heart disease in Chinese women. Int J Obes Relat Metab Disord 28: 734-740.

53. Esmaillzadeh A, Mirmiran P, Azizi F (2004) Waist-to-hip ratio is a better screening measure for cardiovascular risk factors than other anthropometric indicators in Tehranian adult men. Int J Obes Relat Metab Disord 28: 1325 1332.

54. Price GM, Uauy R, Breeze E, Bulpitt CJ, Fletcher AE (2006) Weight, shape, and mortality risk in older persons: elevated waist-hip ratio, not high body mass index, is associated with a greater risk of death. Am J Clin Nutr 84: 449-460.

55. Kizer JR, Biggs ML, Ix JH, Mukamal KJ, Zieman SJ, et al. (2011) Measures of adiposity and future risk of ischemic stroke and coronary heart disease in older men and women. Am J Epidemiol 173: 10-25.

56. Alberti KG, Zimmet PZ (1998) Definition, diagnosis and classification of diabetes mellitus and its complications. Part 1: diagnosis and classification of diabetes mellitus provisional report of a WHO consultation. Diabet Med 15 : 539-553.

57. Okosun IS, Ghogomu TA (2012) Waist-Circumference Phenotype and Risk of Type 2 Diabetes. Handbook of Anthropometry: Springer: 2091-2105.

58. Huxley R, James WP, Barzi F, Patel JV, Lear SA, et al. (2008) Ethnic comparisons of the cross-sectional relationships between measures of body size with diabetes and hypertension. Obes Rev 9 Suppl 1: 53-61.

59. Nyamdorj R (2010) Anthropometric measures of obesity-their association with type 2 diabetes and hypertension across ethnic groups. 
Citation: Millar SR, Perry IJ, Phillips CM (2013) Surrogate Measures of Adiposity and Cardiometabolic Risk - Why the Uncertainty? A Review of Recent Meta-Analytic Studies. J Diabetes Metab S11: 004. doi:10.4172/2155-6156.S11-004

60. Browning LM, Hsieh SD, Ashwell M (2010) A systematic review of waist-toheight ratio as a screening tool for the prediction of cardiovascular disease and diabetes: 0.5 could be a suitable global boundary value. Nutr Res Rev 23 247-269.

61. Ashwell M, Hsieh SD (2005) Six reasons why the waist-to-height ratio is a rapid and effective global indicator for health risks of obesity and how its use could simplify the international public health message on obesity. Int J Food Sci Nutr 56: 303-307.

62. Park YS, Kim JS (2012) Association between waist-to-height ratio and metabolic risk factors in Korean adults with normal body mass index and wais circumference. Tohoku J Exp Med 228: 1-8.

63. Schneider HJ, Glaesmer H, Klotsche J, Böhler S, Lehnert H, et al. (2007) Accuracy of anthropometric indicators of obesity to predict cardiovascular risk. J Clin Endocrinol Metab 92: 589-594.

64. Jayawardana R, Ranasinghe P, Sheriff M, Matthews D, Katulanda P (2013) Waist to height ratio: A better anthropometric marker of diabetes and cardiometabolic risks in South Asian adults. Diabetes Res Clin Pract 99: 292-299.

65. Xu F, Wang YF, Lu L, Liang Y, Wang Z, et al. (2010) Comparison of anthropometric indices of obesity in predicting subsequent risk of hyperglycemia among Chinese men and women in Mainland China. Asia Pac J Clin Nutr 19: 586-593.

66. Hsieh SD, Muto T (2005) The superiority of waist-to-height ratio as an anthropometric index to evaluate clustering of coronary risk factors among nonobese men and women. Prev Med 40: 216-220.

67. Paajanen TA, Oksala NK, Kuukasjärvi P, Karhunen PJ (2010) Short stature is associated with coronary heart disease: a systematic review of the literature and a meta-analysis. Eur Heart J 31: 1802-1809.

68. Sammalisto S, Hiekkalinna T, Schwander K, Kardia S, Weder AB, et al. (2009) Genome-wide linkage screen for stature and body mass index in 3.032 families: evidence for sex- and population-specific genetic effects. Eur J Hum Genet 17 258-266.

69. Barker DJ (1991) The intrauterine origins of cardiovascular and obstructive lung disease in adult life. The Marc Daniels Lecture 1990. J R Coll Physicians Lond 25: 129-133.

70. Ashwell M, Gunn P, Gibson S (2012) Waist-to-height ratio is a better screening tool than waist circumference and BMI for adult cardiometabolic risk factors: systematic review and meta-analysis. Obes Rev 13: 275-286.

71. Ashwell M (2012) Plea for simplicity: use of waist-to-height ratio as a primary screening tool to assess cardiometabolic risk. Clinical Obesity 2: 3-5.

72. Ashwell M, Gibson S (2009) Waist to height ratio is a simple and effective obesity screening tool for cardiovascular risk factors: Analysis of data from the British National Diet And Nutrition Survey of adults aged 19-64 years. Obes Facts 2: 97-103.

73. Kodama S, Horikawa C, Fujihara K, Heianza Y, Hirasawa R, et al. (2012) Comparisons of the strength of associations with future type 2 diabetes risk among anthropometric obesity indicators, including waist-to-height ratio: a meta-analysis. Am J Epidemiol 176: 959-969.

74. Mei Z, Grummer-Strawn LM, Pietrobelli A, Goulding A, Goran MI, et al. (2002) Validity of body mass index compared with other body-composition screening indexes for the assessment of body fatness in children and adolescents. Am J Clin Nutr 75: 978-985.

75. Valdez R, Seidell JC, Ahn YI, Weiss KM (1993) A new index of abdominal adiposity as an indicator of risk for cardiovascular disease. A cross-population study. Int J Obes Relat Metab Disord 17: 77-82.

76. Guerrero-Romero F, Rodri'guez-Morán M (2003) Abdominal volume index. an anthropometry-based index for estimation of obesity is strongly related to impaired glucose tolerance and type 2 diabetes mellitus. Arch Med Res 34 428-432.

77. Krakauer NY, Krakauer JC (2012) A new body shape index predicts mortality hazard independently of body mass index. PLoS One 7: e39504.

78. Armellini F, Zamboni M, Harris T, Micciolo R, Bosello O (1997) Sagittal diameter minus subcutaneous thickness. An easy-to-obtain parameter that improves visceral fat prediction. Obes Res 5: 315-320.

79. Gray DS, Bray GA, Bauer M, Kaplan K, Gemayel N, et al. (1990) Skinfold thickness measurements in obese subjects. Am J Clin Nutr 51: 571-577.

80. Durnin JV, Rahaman MM (1967) The assessment of the amount of fat in the human body from measurements of skinfold thickness. Br J Nutr 21: 681-689.
81. Bergman RN, Stefanovski D, Buchanan TA, Sumner AE, Reynolds JC, et al. (2011) A better index of body adiposity. Obesity (Silver Spring) 19: 1083-1089.

82. Gómez-Ambrosi J, Silva C, Catalán V, Rodríguez A, Galofré JC, et al. (2012) Clinical usefulness of a new equation for estimating body fat. Diabetes Care 35: 383-388.

83. Lee CM, Huxley RR, Wildman RP, Woodward M (2008) Indices of abdomina obesity are better discriminators of cardiovascular risk factors than BMI: a meta-analysis. J Clin Epidemiol 61: 646-653.

84. Decoda Study Group, Nyamdorj R, Qiao Q, Lam TH, Tuomilehto J, et al. (2008) BMl compared with central obesity indicators in relation to diabetes and hypertension in Asians. Obesity (Silver Spring) 16: 1622-1635.

85. van Dijk SB, Takken T, Prinsen EC, Wittink H (2012) Different anthropometric adiposity measures and their association with cardiovascular disease risk factors: a meta-analysis. Neth Heart J 20: 208-218.

86. Obesity in Asia Collaboration (2008) Is central obesity a better discriminator of the risk of hypertension than body mass index in ethnically diverse populations? J Hypertens 26: 169-177.

87. Carmienke S, Freitag MH, Pischon T, Schlattmann P, Fankhaenel T, et al. (2013) General and abdominal obesity parameters and their combination in relation to mortality: a systematic review and meta-regression analysis. Eur $J$ Clin Nutr 67: 573-585.

88. Czernichow S, Kengne AP, Stamatakis E, Hamer M, Batty GD (2011) Body mass index, waist circumference and waist-hip ratio: which is the bette discriminator of cardiovascular disease mortality risk? Evidence from an individual-participant meta-analysis of 82864 participants from nine cohort studies. Obes Rev 12: 680-687.

89. Vazquez G, Duval S, Jacobs DR Jr, Silventoinen K (2007) Comparison of body mass index, waist circumference, and waist/hip ratio in predicting incident diabetes: a meta-analysis. Epidemiol Rev 29: 115-128.

90. de Koning L, Merchant AT, Pogue J, Anand SS (2007) Waist circumference and waist-to-hip ratio as predictors of cardiovascular events: meta-regression analysis of prospective studies. Eur Heart J 28: 850-856.

91. Coutinho T, Goel K, Corrêa de Sá D, Kragelund C, Kanaya AM, et al. (2011) Central obesity and survival in subjects with coronary artery disease: a systematic review of the literature and collaborative analysis with individual subject data. J Am Coll Cardiol 57: 1877-1886.

92. Peat J, Barton B (2008) Medical statistics: A guide to data analysis and critical appraisal: BMJ Books.

93. Huxley R, Mendis S, Zheleznyakov E, Reddy S, Chan J (2010) Body mass index, waist circumference and waist:hip ratio as predictors of cardiovascula risk--a review of the literature. Eur J Clin Nutr 64: 16-22.

94. Kodama S, Horikawa C, Fujihara K, Heianza Y, Hirasawa R, et al. (2012) Comparisons of the strength of associations with future type 2 diabetes risk among anthropometric obesity indicators, including waist-to-height ratio: a meta-analysis. Am J Epidemiol 176: 959-969.

55. Guasch-Ferré M, Bulló M, Martínez-González MÁ, Corella D, Estruch R, et al. (2012) Waist-to-height ratio and cardiovascular risk factors in elderly individuals at high cardiovascular risk. PLoS One 7: e43275.

96. Huerta JM, Tormo MJ, Chirlaque MD, Gavrila D, Amiano P, et al. (2013) Risk of type 2 diabetes according to traditional and emerging anthropometric indices in Spain, a Mediterranean country with high prevalence of obesity: results from a large-scale prospective cohort study. BMC Endocrine Disorders 13: 7.

97. InterAct Consortium, Langenberg C, Sharp SJ, Schulze MB, Rolandsson O, et al. (2012) Long-term risk of incident type 2 diabetes and measures of overall and regional obesity: the EPIC-InterAct case-cohort study. PLoS Med 9: e1001230.

98. Wannamethee SG, Papacosta O, Whincup PH, Carson C, Thomas MC et al. (2010) Assessing prediction of diabetes in older adults using different adiposity measures: a 7 year prospective study in 6,923 older men and women. Diabetologia 53: 890-898.

99. Mooney SJ, Baecker A, Rundle AG (2012) Comparison of anthropometric and body composition measures as predictors of components of the metabolic syndrome in a clinical setting. Obesity Research \& Clinical Practice 7: e55-e66.

100. Pepe MS, Janes H, Longton G, Leisenring W, Newcomb P (2004) Limitations of the odds ratio in gauging the performance of a diagnostic, prognostic, or screening marker. Am J Epidemiol 159: 882-890. 
Citation: Millar SR, Perry IJ, Phillips CM (2013) Surrogate Measures of Adiposity and Cardiometabolic Risk - Why the Uncertainty? A Review of Recent Meta-Analytic Studies. J Diabetes Metab S11: 004. doi:10.4172/2155-6156.S11-004

101. Qiao Q, Nyamdorj R (2010) Is the association of type II diabetes with waist circumference or waist-to-hip ratio stronger than that with body mass index? Eur J Clin Nutr 64: 30-34.

102. Ho S, Chen Y, Woo J, Leung S, Lam T, et al. (2001) Association between simple anthropometric indices and cardiovascular risk factors. International journal of obesity 25: 1689-1697.

103. Janssen I, Katzmarzyk PT, Ross R (2004) Waist circumference and not body mass index explains obesity-related health risk. Am J Clin Nutr 79: 379-384.

104. Rostambeigi N, Shaw JE, Atkins RC, Ghanbarian A, Cameron AJ, et al. (2010)
Waist circumference has heterogeneous impact on development of diabetes in different populations: Longitudinal comparative study between Australia and Iran. Diabetes Res Clin Pract 88: 117-124.

105. Janiszewski PM, Janssen I, Ross R (2007) Does waist circumference predict diabetes and cardiovascular disease beyond commonly evaluated cardiometabolic risk factors? Diabetes Care 30: 3105-3109.

106. Phillips CM, Tierney AC, Perez-Martinez P, Defoort C, Blaak EE, et al. (2012) Obesity and body fat classification in the metabolic syndrome: impact on cardiometabolic risk metabotype. Obesity (Silver Spring. [Epub ahead of print] 